\title{
Fire Protection Ability of Wood Coverings
}

\author{
Birgit A-L Östman
}

\begin{abstract}
The low thermal conductivity and slow charring rate of wood products may protect underlying products from being heated and ignited. A literature survey shows that such fire protective behavior of wood coverings has been verified by different methodologies in several countries in and outside Europe. A new European system with $\mathrm{K}$ classes for the fire protection ability of coverings has been utilized for wood products. The classes are based on full-scale furnace testing, and the main parameter is the temperature behind the fire-exposed panel after different time intervals. Three levels are defined: 10, 30 and $60 \mathrm{~min}$. An extensive test program has been performed according to the new European system. The results demonstrate that all $\mathrm{K}$ classes may be achieved for wood-based panels (particle board, plywood, solid wood panels, OSB - Oriented Strand Board and hardboard), and for solid wood panelling and cladding. The criteria for wood products are based mainly on panel thickness. The thickness for achieving each $\mathrm{K}$ class may vary slightly, depending on the wood product type and on mounting conditions and fixing means. Typical thickness to reach $10 \mathrm{~min}$ fire protection is $10-15 \mathrm{~mm}$, for $30 \mathrm{~min} 24$ $-30 \mathrm{~mm}$, and for $60 \mathrm{~min}$ protection $52-54 \mathrm{~mm}$. The enduse applications of wood products with $\mathrm{K}$ classes are mainly as wall and ceiling coverings and for protection of underlying materials and structures. Examples are protection of timber structures from becoming charred, and protection of steel structures from reaching high temperatures. $\mathrm{K}$ classification is required by building regulations in some countries, e. g. Germany, Denmark and Sweden.
\end{abstract}

KEYWORDS : Fire Protection, Heat Insulation, Wood Products, Structural Design, Temperature Rise

\section{Introduction}

The low thermal conductivity and slow charring rate of wood products may protect underlying materials from being heated and ignited. A literature survey shows that such fire protective behavior of wood coverings has been verified by different methodologies in several countries in and outside Europe. These studies have often been performed to demonstrate the use of component additive methods to calculate the separational fire resistance of wood assemblies and to provide input data (Norén and Östman 1985, König et al. 2000) to be used for modelling, e. g. in the fire part of Eurocode 5 (EN 1995-12), the structural design code for Europe. Eurocode 5 uses the term 'basic insulation value' which is closely related to the fire protection ability.

A European system with $\mathrm{K}$ classes for the fire protection ability of building panels has been introduced and is defined in (EN 13501-2). The $\mathrm{K}$ classes are based on fullscale furnace testing in horizontal orientation according to (EN 14135), and the main parameter is the temperature behind the panel after different time intervals (10, 30 and $60 \mathrm{~min}$ ). No collapse or falling parts are allowed. The test principle is illustrated in Figure 1.

The aim of the $\mathrm{K}$ classes is to provide fire protection of underlying parts of a structure, e.g. the insulation in a wall or floor element. Two types of $\mathrm{K}$ classes are defined, depending on the substrate behind. Class K1 10 includes substrates with density less than $300 \mathrm{~kg} / \mathrm{m} 3$, while Classes K2 10 - K2 60 include all substrates, so in practice it is sufficient to verify K2 classes. Class K1 10 is used and required only in Denmark.

The $\mathrm{K}$ classes originate from the Nordic countries, where they have been used mainly for gypsum plasterboards, since the Nordic criteria also include reaction-to-fire requirements. However, in the European system, only fire 


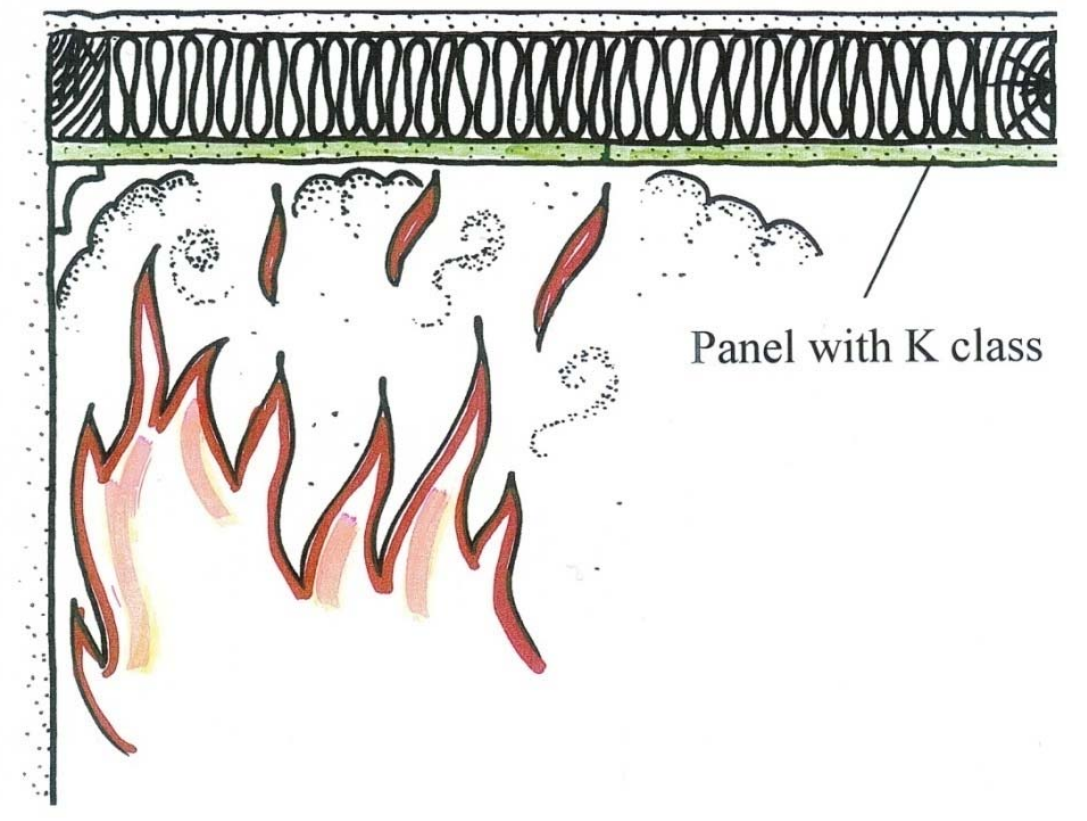

Figure 1. Principle for Testing Fire Protection Ability According to EN 14135.

resistance criteria prevail, so this is a great opportunity for wood products to demonstrate their fire protection abilities.

Most of the previous work has been performed in modelscale furnaces of different sizes with either a wood substrate, a mineral insulation product or a cavity behind. The case with mineral insulation behind is generally considered to be the worst case. Only some of the US data (White $1982 \mathrm{a}$ and b, White 2003) include foam plastic insulations as substrate. The criteria for temperature increase behind the panel have usually been either 140 or $250 \mathrm{~K}$, but this has been neglected in the present analysis, since the temperature increase is quite rapid at these temperatures and results in only about one minute difference or less.

It is obvious from the literature review that panel thickness is the most important factor for the contribution to fire resistance for both wood-based panels and gypsum plasterboards. Density has generally a minor effect at mean densities about $500-700 \mathrm{~kg} / \mathrm{m} 3$, which include most wood products.

Similar thickness of the wood products to reach 10 and 30 min fire protection has been demonstrated. These data are promising for reaching European $\mathrm{K}$ class, but the methodologies used have been different, so further testing according to the European standards is needed to reach the European $\mathrm{K}$ classes.
A summary of the test results and literature data has been published (Östman and Boström 2014). Full data are presented in (Östman et al. 2014). Partial results are included in technical guidelines (Östman et al. 2014).

\section{Fire Testing and Classification}

An extensive test program on verifying $\mathrm{K}$ class for different wood products has been performed using exactly the European standard methodology required. The wood products have been tested in a horizontal furnace according to the European test method Coverings - Determination of fire protection ability (EN 14135).

Different thicknesses of covering, design and geometry for joints and fixing methods of the products are included. In each test, two full size specimens 3,0 x 2,4 m were included. A series of pretesting with smaller elements $1,0 \times 2,4 \mathrm{~m}$ was also performed.

\section{Mounting and Fixing}

All products were mounted on the substrate prescribed in EN 14135, $19 \mathrm{~mm}$ chipboard $680 \mathrm{~kg} / \mathrm{m3}$, without any air gap or cavity behind.

The coverings were fixed to the substrate in the same way as in practice, i.e. with screws for all wood-based panels except hardboards/medium board, where brads were used, and with nails for solid wood panelling and cladding.

All elements consisted of segments of the tested covering with joints according to EN 14135. The supporting system consisted of a framework of wooden beams with cc $600 \mathrm{~mm}$ and the chipboard substrate was mounted on the lower side of the framework.

Further details on the mounting and fixing are given in (Östman et al. 2014, Hilling and Boström 2009, Hilling et al. 2009).

Typical design of test elements and instrumentation of full size specimen is shown in Figure 2.

\section{Furnace control}

The furnace was controlled in accordance with EN 13631 to follow the standard time / temperature curve. The furnace temperature was measured with five plate thermometers and the measuring junctions were positioned approximately $100 \mathrm{~mm}$ below the fire-exposed 

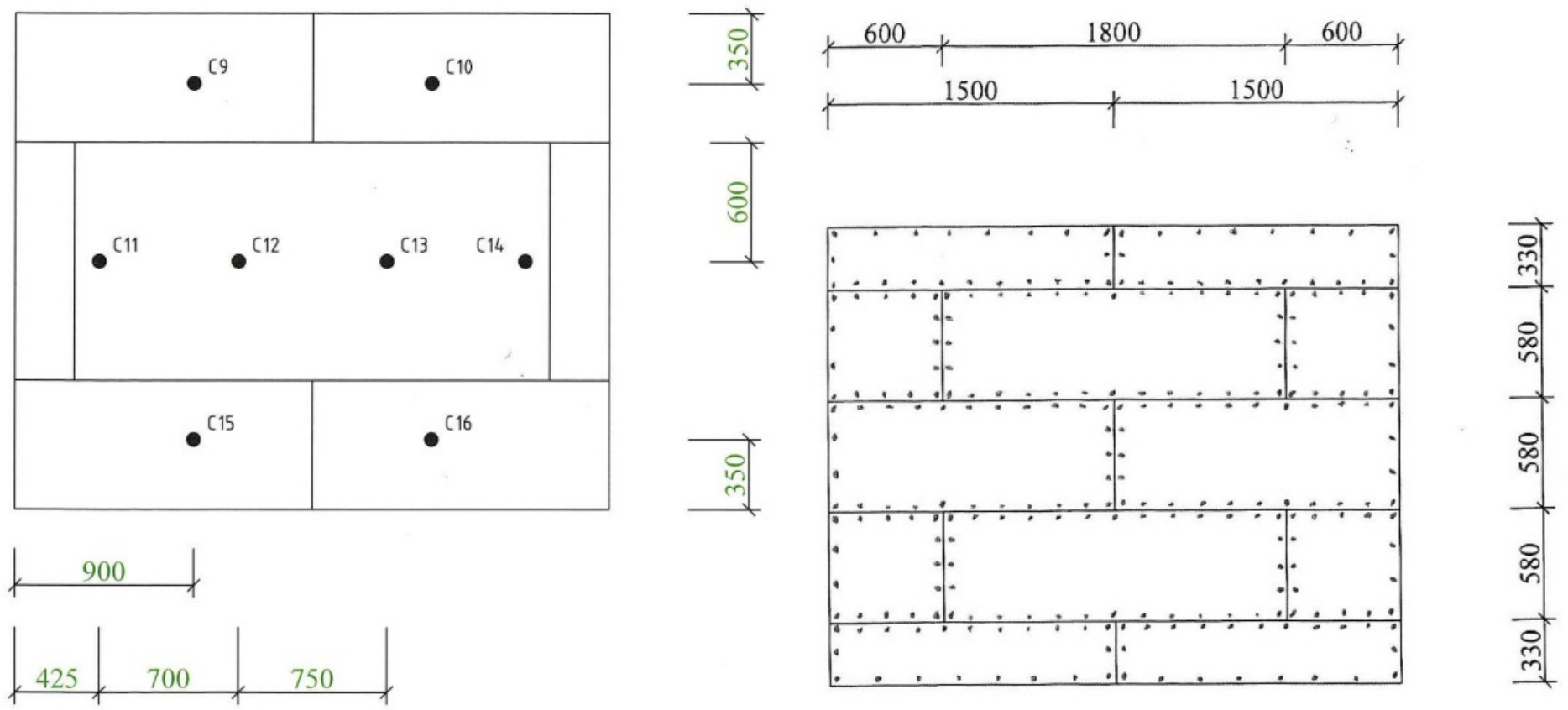

Figure 2. Typical Design of Segments in a Full Size Tested Covering $3.0 \times 2.4 \mathrm{~m}$ with Joints According to EN 14135. Thermocouples between the tested covering and the substrate are shown on the left, and typical screw spacing on the right (screw size and edge distance not to scale) (Hilling et al. 2012).

surface at the commencement of the test. The average temperature and the temperature of each plate thermometer were recorded and reported in the test reports.

The pressure in the furnace in relation to the ambient pressure in the test hall was measured and controlled $100 \mathrm{~mm}$ below the fire-exposed surface of the test specimen. The furnace was controlled to an overpressure of approximately $20 \mathrm{~Pa}$.

\section{Measurements and Observations}

The temperature rise on the lower side of the chipboard substrate was measured with 8-9 thermocouples for the full size elements and recorded. Photographs were taken before and after the test.

After the test, the tested covering was inspected for collapse and the chipboard substrate for charring.

\section{Fire Classification Criteria}

A covering designated $\mathrm{K} 2$ as defined in EN 13501-2 is considered to give the prescribed protection for materials behind the covering if, during a test in accordance with EN 14135, there is no collapse of the covering or parts of it within the classification period (10 $\mathrm{min}, 30 \mathrm{~min}$ or 60 min), and also if the following requirements are fulfilled.

For a covering without a cavity or cavities behind it:
- the mean temperature measured on the lower side of the substrate shall not exceed the initial temperature by more than $250 \mathrm{~K}$

- the maximum temperature measured at any point of this side shall not exceed the initial temperature by more than $270 \mathrm{~K}$, and

- after the test, there shall be no burnt, charred, melted or shrunk material at any point of the substrate.

For a covering with a cavity or cavities behind it:

- the mean temperature measured on the lower side of the substrate and the mean temperature measured on the unexposed side of the covering shall not exceed the initial temperature by more than $250 \mathrm{~K}$

- the maximum temperature measured at any point of these sides shall not exceed the initial temperature by more than $270 \mathrm{~K}$, and

- $\quad$ after the test, there shall be no burnt, charred, melted or shrunk material at any point of the substrate and at any point of the unexposed side of the covering. 
Table 1. Wood Products Tested

\begin{tabular}{cccccc}
\hline Wood Product & $\begin{array}{c}\text { EN Harmonized } \\
\text { Product Standard }\end{array}$ & Thickness, $\mathrm{mm}$ & $\begin{array}{c}\text { Mean Density, } \\
\mathrm{kg} / \mathrm{m}^{3}\end{array}$ & $\begin{array}{c}\text { Fixing Device } \\
\text { (nail, screw, etc.) }\end{array}$ & Joints \\
\hline Particleboard & EN 13986 & $10,12,22,25$ & $580-680$ & Screw & $\begin{array}{c}\text { Square Edges, } \\
\text { Tongue and } \\
\text { Groove (T\&G) }\end{array}$ \\
Plywood & EN 13986 & $9,12,24$ & $470-530$ & Screw & $\begin{array}{c}\text { Square Edges, } \\
\text { T\&G }\end{array}$ \\
Hardboard & EN 13986 & 9 & 770 & Brad & $\begin{array}{c}\text { Square Edges } \\
\text { OSB }\end{array}$ \\
EN 13986 & $10,12,25,30$ & $590-600$ & Screw & $\begin{array}{c}\text { Square Edges, } \\
\text { T\&G }\end{array}$ \\
SWP & EN 13986 & $13,26,52$ & $440-490$ & Screw & $\begin{array}{c}\text { Square Edges, } \\
\text { T\&G }\end{array}$ \\
SWPC & EN 14915 & 15,27 & $450-460$ & Nail & T\&G \\
\hline
\end{tabular}

\section{Wood Products Tested}

Different types of wood products according to the European harmonized standards EN 13986 and EN 14915 have been tested, five types of wood-based panels (particle board, plywood, oriented strand board (OSB), hardboard/medium board and multilayer solid wood panels (SWP)) and solid wood paneling and cladding (SWPC), see Table 1.

\section{Joints and fixing devices}

The joints within a wood element were either with square edges or with tongue and groove profiles without gaps. Typical design is given in Figure 3. The thickness at the joints was the same as for the wood product.

The fixing devices were chosen according to industry guidance and producers' recommendations, see Table 2 . The edge distance was $3 d$ (nominal diameter) for woodbased panels and $5 d$ for SWPC. All dimensions of the fixing devices used are included for completeness.

\section{Fire test results and analysis}

Typical examples of pictures from the EN 14135 fire tests are shown in Figure 4 and 5.

The pretest results with smaller $1,0 \times 2,4 \mathrm{~m}$ specimens for 10 and 30 minutes exposure time (Hilling and Boström) showed that all temperatures were below the
Table 2. Fixing Devices Used for Wood Products

\begin{tabular}{clcc}
\hline $\begin{array}{l}\text { Fixing } \\
\text { Device }\end{array}$ & $\begin{array}{l}\text { Length/ } \\
\text { Diameter (d), } \\
\mathrm{mm}\end{array}$ & $\begin{array}{l}\text { Spacing } \\
\text { at Edge, } \\
\mathrm{mm}\end{array}$ & Used For: \\
\hline Screw & $\begin{array}{l}\text { 25/2.5,30/3.5, } \\
\text { 30/3.9,30/4.2, } \\
41 / 4.2,50 / 3.5, \\
57 / 4.2,75 / 4.1\end{array}$ & & $\begin{array}{c}\text { Particleboard, } \\
\text { OSB, Plywood, } \\
\text { SWP }\end{array}$ \\
Brad & $\begin{array}{c}\text { 40/1.7 } \\
\text { Nail }\end{array}$ & $\begin{array}{c}50 / 2.0,50 / 3.0, \\
60 / 2.3\end{array}$ & Hardboard \\
& 600 & SWPC \\
\hline
\end{tabular}

maximum temperature rise, so standard testing with fullsize elements started.

The fire test results for the full size elements at all fire exposure times (Hilling et al. 2009) have been analyzed in terms of panel thickness, type of wood product, joints and char at substrate. The results are shown in Figures 6 and 7 .

Most tested products with no char at substrate also passed the temperature rise criterion of $<250 \mathrm{~K}$ at substrate. But some of the products passing the temperature criterion had some char at the substrate behind the covering. The charring was caused by heat
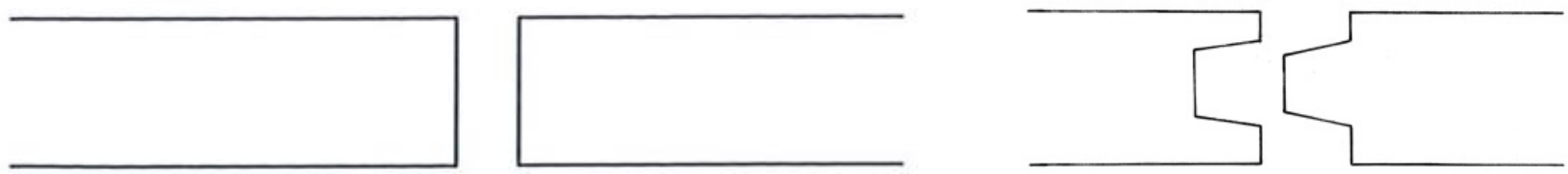

Figure 3. Typical Design of Joints with Square Edges (left) or with Tongue and Groove (right). 


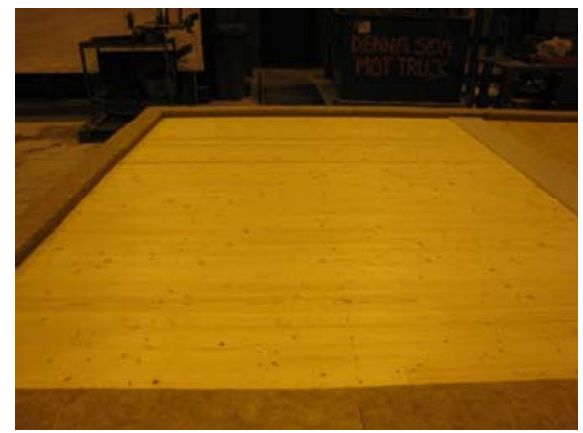

(a)

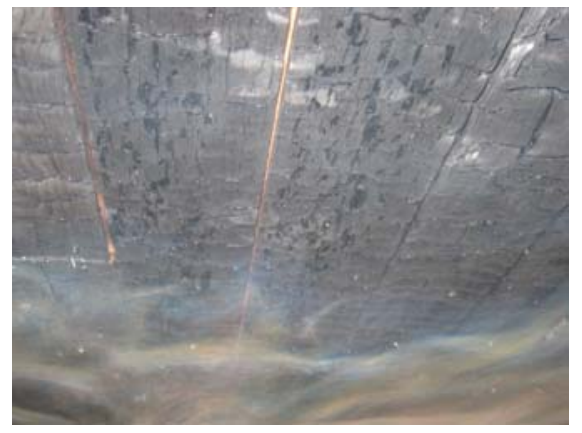

(b)

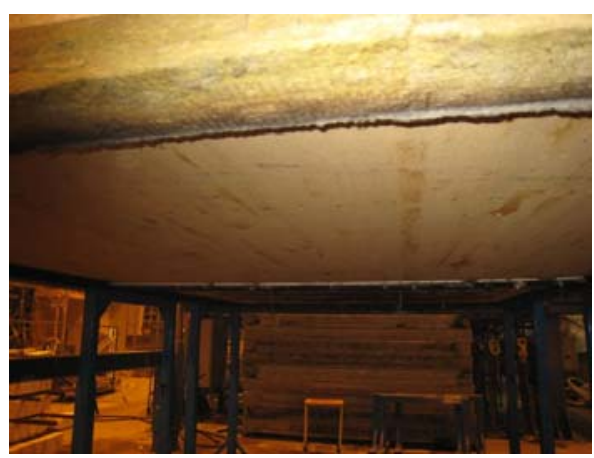

(c)

Figure 4. Testing Solid Wood Panelling. (a) The Exposed Side of the Wood Covering Before, and (b) After Fire Testing. (c) The Substrate Behind the Covering After the Fire Testing.

exposure at joints or fixing devices. However, no difference between butt (square) and $\$$ \& joints could be observed, see lower diagram in Figure 7.

The conclusion is that the EN 13501-2 requirements for both maximum temperature rise on the substrate and lack of charring are useful as test criteria.

The fire protection ability of wood products with different thicknesses is illustrated in Figure 7. The dependence on panel thickness is clear. The real protection time is longer, but not recorded, since the tests had to be terminated at the exact end times according to EN 14135 in order to be able to observe possible charring at the substrate.

The pretesting and the full size data are quite similar, especially at $10 \mathrm{~min}$ fire exposure, for which most of the tests were performed (Östman and Boström 2014).

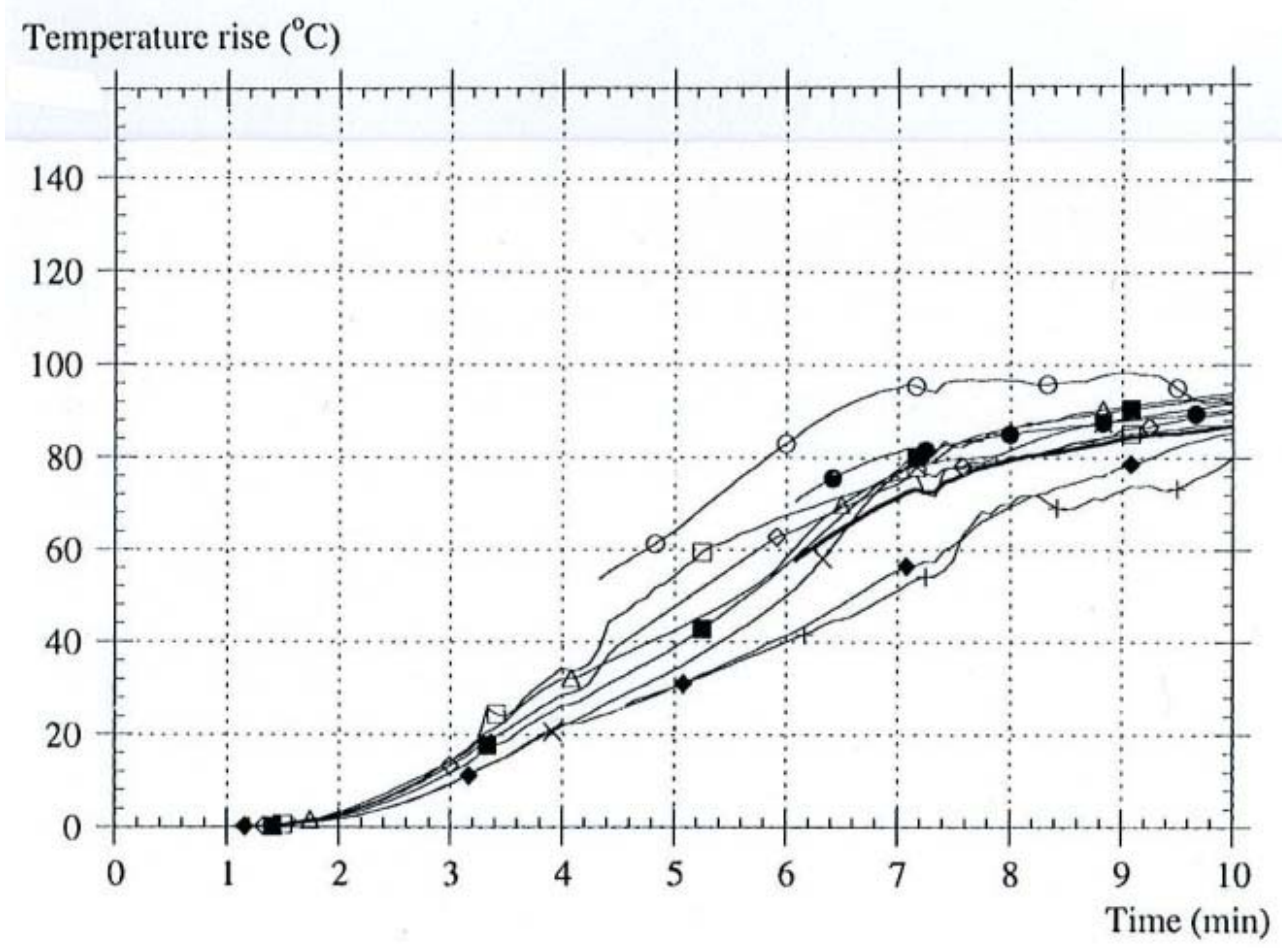

Figure 5. Example of Measured Temperature Behind the Tested Solid Wood Panelling. 
Figure 6. Full-Scale Test

Results as Maximum

Temperature Rise at the

Substrate Behind the Tested

Covering at Exposure Times

10, 30 and 60 Min.

Above: For Wood Products

with No Char at the

Substrate Behind the

Covering.

Below: For Wood Products with Char at Substrate. All Charring Appeared at the Joints or Fixing Devices.
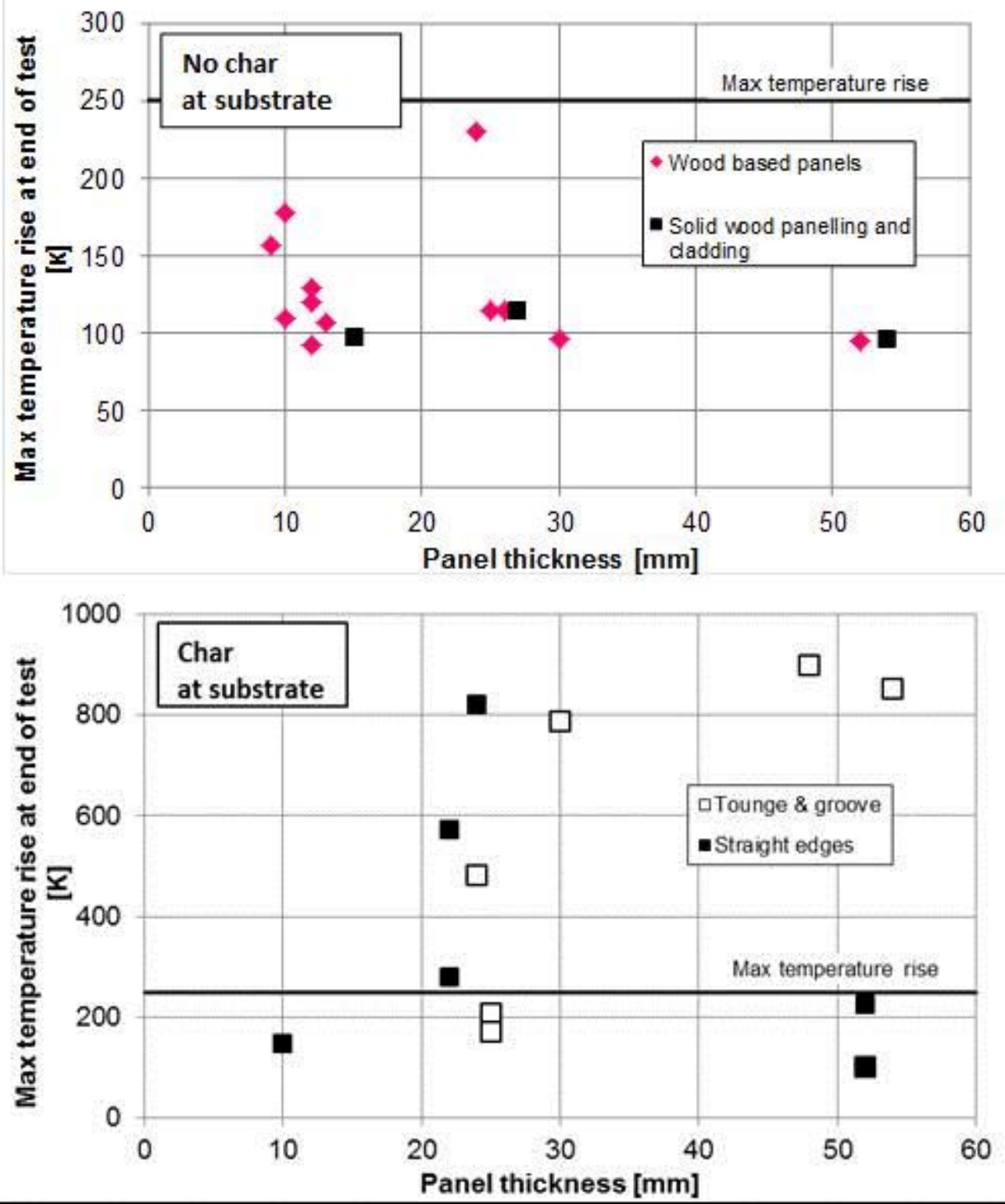

\section{$K$ classes for wood products}

The classification of the fire protection ability of the wood products tested has been performed according to the CWFT - Classification Without Further Testing procedure (CONSTRUCT 2004). This procedure may be used for products which have been proven to be stable in a given European class. CWFT is a list of generic products, not a list of proprietary products. Products claiming CWFT must be clearly above the lower class limits, to provide a safety margin.

Wood products are good examples of products having a stable fire performance. The CWFT approach has earlier been applied for the reaction to fire performance of several wood products. Results have been published e.g. (Östman and Mikkola 2006). The request for $\mathrm{K}$ classes is the first CWFT case dealing with fire resistance performance.
Detailed documentation has been supplied to the European Commission services. The documentation was carefully checked in several steps and at different levels and finally approved by SCC, the European Standing Committee on Construction. The final classification is published in the Official Journal of the European Commission (COMMISSION DELEGATED REGULATION 2014).

In all cases, the criteria according to EN 13501-2 were fulfilled:

The maximum temperature rise behind the covering was less than $250 \mathrm{~K}$

There was no char on the substrate behind the covering The safety margin to the class limit is generally very large and in average $>100 \mathrm{~K}$. 
Figure 7. The Fire Protection

Ability (Time) According to

EN 14135 for Wood-Based

Panels and Solid Wood

Panelling with Different

Thicknesses Tested at 10, 30

and 60 Minutes (Hilling et al.

2012).

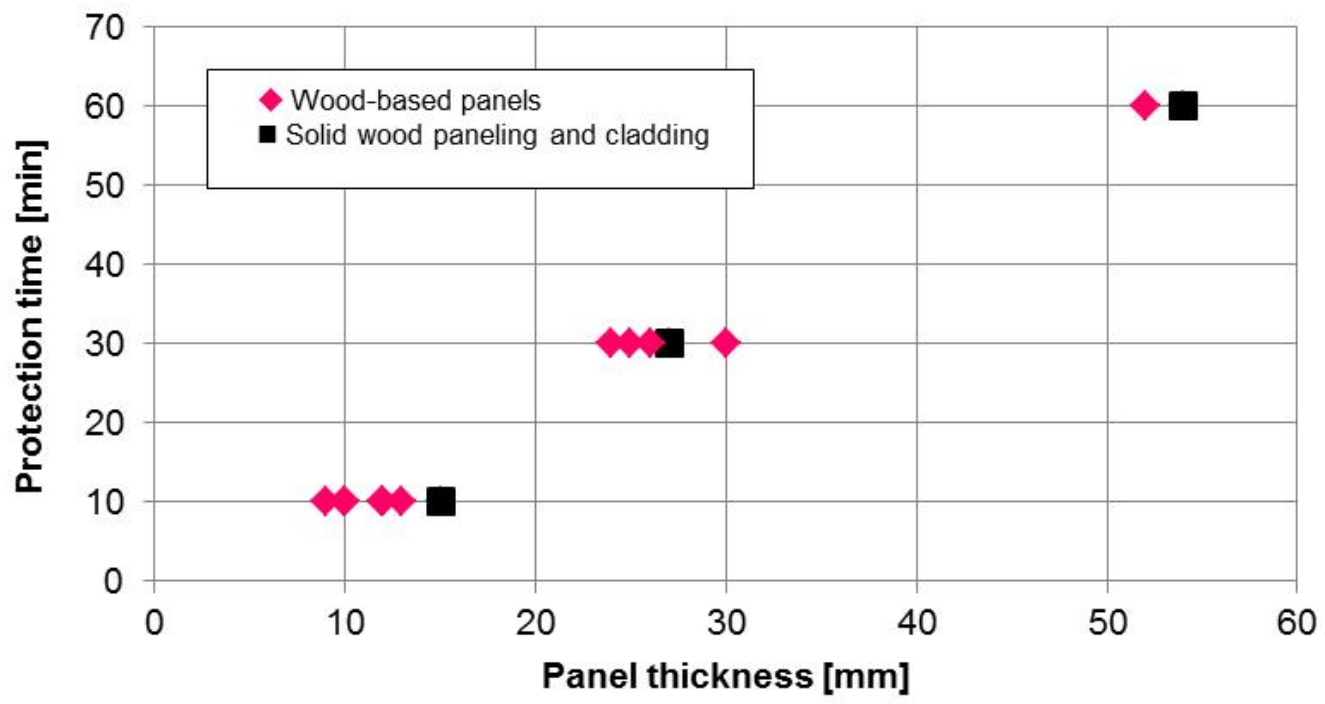

\section{Conclusions and Applications}

The main product parameter influencing the fire protection ability of wood-based panels and solid wood panelling and cladding is thickness, while density has a minor influence for the density ranges studied.

Wood-based panels, i.e. particle board, plywood, OSB and solid wood panels (according to EN 13986) at least $10 \mathrm{~mm}$ thick, and hardboard/medium board at least $9 \mathrm{~mm}$ thick fulfil Classes K1 10 (for substrates $\geq 300 \mathrm{~kg} / \mathrm{m} 3$ ) and K2 10. Wood-based panels and solid wood panels at least $24-30 \mathrm{~mm}$ thick fulfil Class K2 30 . Solid wood panels at least $52 \mathrm{~mm}$ thick fulfil Class K2 60 .

Solid wood panelling and cladding (according to EN 14915) planed with tongue and groove joints and with equal thicknesses of at least $15 \mathrm{~mm}$ fulfil Classes K1 10 (for substrates $\geq 300 \mathrm{~kg} / \mathrm{m} 3$ ) and K2 10 . Solid wood panelling and cladding at least $27 \mathrm{~mm}$ thick fulfil Class $\mathrm{K} 2$ 30 , and of at least $2 \times 27 \mathrm{~mm}$ thick fulfil Class K2 60 .

Wood-based products fulfilling the different $\mathrm{K}$ classes are summarised in Table 4 (COMMISSION DELEGATED REGULATION 2014).

The end-use applications of K-classified wood products are mainly wall and ceiling coverings and for protection of underlying materials. Examples are protection of timber structures from being charred, and protection of steel structures from reaching high temperatures. $\mathrm{K}$ classes are required by building regulations in some countries, e.g. Germany, Denmark and Sweden.

\section{Acknowledgements}

Public financial support from the European WoodWisdom -Net program and Vinnova Sweden's Innovation Agency and industry financial support from the European initiative Building with wood (BWW) via CEI-Bois, the Swedish Forest Industries Federation and TMF Trä - och Möbelföretagen is kindly acknowledged. The Nordic companies Swedspan, Forestia, Vänerply and UPM have contributed both financially and by supplying some of the tested products. The research work has been carried out at SP Wood Technology and the fire testing at SP Fire Technology (now SP Fire Research). Special thanks to Rolf Hilling for excellent technical assistance and support.

\section{References}

Classification of products of known and stable performance - Procedural aspects. CONSTRUCT 01/491 rev 3, 2004.

COMMISSION DELEGATED REGULATION (EU) No 1291/2014. Official Journal of the European Union. L 349/25. 5.12.2014.

EN 1995-1-2. Eurocode 5 - Design of timber structures. Part 1-2: General rules - Structural fire design. European Standard.

EN 13501-2. Fire classification of construction products and building elements - Part 2: Classification using data from fire resistance tests, excluding ventilation services. European Standard.

EN 13986. Wood-based panels for use in construction Characteristics, evaluation of conformity and marking. European Standard. 
EN 14135. Coverings - Determination of fire protection ability. European Standard.

EN 14915. Solid wood panelling and cladding Characteristics, evaluation of conformity and marking. European Standard.

Hilling $R$ and Boström L. Development fire test of six coverings. SP Test Reports P905327, parts 01A, 01B, 01C and $01 \mathrm{H}, 2009-2010$.

Hilling $R$ et al. Fire test of a covering. SP Test Reports P905327. Totally 30 parts 01D-01V2, 2009-2012.

König J, Oksanen T and Towler K. A review of component additive method used for the determination of fire resistance of separating light timber frame structures, CIB W18 Paper 33-16-3, 2000.

NFPA 275 Standard Method of Fire Tests for the Evaluation of Thermal Bariers Used over Foam Plastic Insulation, 2009.

Norén $\mathrm{J}$ and Östman B. Contribution to fire resistance from building panels. Proc First International Symposium Fire Safety Science 325-335, Washington, 1985.

Östman B et al. Fire safety in timber building - Technical guideline for Europe. SP Report 2010:19, 2010.
Östman B and Boström L. Fire Technology. DOI: 10.1007/s10694-014-0452-z. Published online 17 December 2014.

Östman B, Hilling R and Boström L. Fire protection performance of wood products. SP Report 2012:12, Technical Research Institute of Sweden, 2014.

Östman B and Mikkola E. European classes for the reaction to fire performance of wood products. Holz als Roh- und Werkstoff 64:327-337, 2006.

White R H. Wood-based Paneling Thermal Barriers. Forest Products Laboratory, Research Paper FPL 408, 1982a.

White $\mathrm{R} \mathrm{H}$. Effect of calcium silicate substrate on thermal barrier fire testing. Forest Products J Vol 32, 7, 1982b.

White R H. Fire Resistance of Engineered Rim Board Products. Forest Products Laboratory, Research Paper FPL-RP-610, 2003.

Birgit A-L Östman is Research Leader at SP Trätek in Stockholm, Sweden. birgit.ostman@sp.se. 